\title{
APLIKASI PROSES TEMPERING UNTUK OPTIMASI TITIK LELEH COKELAT HITAM PRODUK PENGOLAHAN PINTAS
}

\section{EFFECT OF TEMPERING ON MELTING POINT AND STICKINESS OF DARK CHOCOLATE}

\author{
Subandrio*), A. Sofian Nasori, Astuti, Lamhot P. Manalu \\ Pusat Teknologi Agroindustri, Deputi TAB, Badan Pengkajian dan Penerapan Teknologi \\ Gedung 612 LAPTIAB, Kawasan Puspiptek, Serpong, Tangerang Selatan 15314 \\ Email: subandrio@bppt.go.id
}

Makalah: Diterima 5 Agustus 2018; Diperbaiki 20 November 2018; Disetujui 27 November 2018

\begin{abstract}
This research is to study the effect of tempering conditions on the change of melting point of dark chocolate produced through a stage of heating and cooling with the stirring process at low-speed. Melting point, hardness, and stickiness were measured in the combination of three different tempering conditions: low temperature $\left(29^{\circ} \mathrm{C}, 31^{\circ} \mathrm{C}\right.$, and $\left.33^{\circ} \mathrm{C}\right)$, high temperature $\left(45^{\circ} \mathrm{C}, 47.5^{\circ} \mathrm{C}\right.$, and $\left.50^{\circ} \mathrm{C}\right)$, and tempering time $(10$ minutes, 17.5 minutes, and 25 minutes). Optimum tempering conditions were evaluated using Response Surface Method (RSM). The best tempering condition was obtained at the combination of low temperature at $31^{\circ} \mathrm{C}$, high temperature at $47.5^{\circ} \mathrm{C}$, and tempering time at 17.5 minutes. This combination resulted melting point, hardness, and stickiness at $36.5^{\circ} \mathrm{C}, 746.3 \mathrm{~g}$, and $-89.941 \mathrm{~g}$ respectively. Thus, attainment of optimum tempering condition was central to the desired properties of produce which melt at human body temperature with the minimum level of hardness at room temperature. The best chocolate product is easily melted at human body temperature, but it is hard at room temperature and also have a minimum adhesiveness cause.
\end{abstract}

Keywords : chocolate, hardness, melting point, response surface method, tempering

\section{ABSTRAK}

Penelitian ini bertujuan untuk mengetahui pengaruh proses tempering terhadap perubahan titik leleh cokelat hitam melalui suatu tahapan proses meliputi pemanasan, pendinginan dan pengadukan dengan kecepatan rendah. Dengan menggunakan rancangan percobaan Response Surface Method (RSM) pada tiga faktor kondisi percobaan yakni temperatur rendah $\left(29,31\right.$ dan $\left.33^{\circ} \mathrm{C}\right)$, temperatur tinggi $\left(45,47,5\right.$ dan $\left.50^{\circ} \mathrm{C}\right)$ dan waktu tempering (10, 17,5 dan 25 menit) terhadap karakteristik produk cokelat yang dihasilkan. Kondisi proses tempering terbaik adalah pada temperatur rendah $31^{\circ} \mathrm{C}$, temperatur tinggi $47,5^{\circ} \mathrm{C}$ dan waktu proses 17,5 menit. Pada kondisi tersebut diperoleh cokelat dengan titik leleh $36,5^{\circ} \mathrm{C}$, kekerasan $746,3 \mathrm{~g}$ dan kuat lengket $-89,941 \mathrm{~g}$. Sifat fisik titik leleh lemak cokelat yang diperoleh ini sudah ideal karena sudah mendekati temperatur tubuh manusia dengan tingkat kekerasan yang minimum pada temperatur kamar. Produk cokelat yang baik adalah yang mudah meleleh pada temperatur tubuh manusia tetapi tidak mudah leleh pada temperatur kamar serta memiliki faktor kuat lengket yang minimum.

Kata kunci : cokelat, kekerasan, response surface method, tempering, titik leleh

\section{PENDAHULUAN}

Kakao (Theobroma cacao) merupakan tanaman tahunan yang berasal dari Amerika Selatan. Tanaman ini menghasilkan biji kakao yang dengan serangkaian proses pengolahan menghasilkan produk antara (intermediate product) berupa pasta (liquor), lemak (butter) dan bubuk (powder). Produk antara kemudian diolah hingga menghasilkan cokelat yang digunakan sebagai bahan utama untuk berbagai produk olahan seperti cokelat batang, kue, es krim, makanan ringan dan aneka minuman cokelat (Manalu, 2016).

Cokelat adalah sebutan untuk hasil olahan makanan atau minuman berbasis produk antara kakao. Cokelat pada umumnya mengandung bubuk cokelat dan lemak kakao yang dicampur dengan bahan-bahan lain seperti gula, susu, emulsifier (lechitin) dan vanila. Campuran ini menjadi dasar untuk diolah kembali menjadi aneka produk cokelat lainnya. Produk campuran dasar ini dalam bentuk blok dikenal dengan nama couverture. Couverture merupakan jenis cokelat terbaik dengan persentase lemak kakao yang tinggi sehingga menghasilkan flavor yang sangat baik. Bila komponen lemak kakao disubstitusi dengan lemak nabati yang lebih murah maka bentuk bloknya dinamakan compound (Jahurul et al., 2013). Cokelat yang beredar di Indonesia umumnya menggunakan cocoa butter substitute (CBS) yang berupa lemak nabati sawit (Lipp dan Anklam, 1998; Manalu et al., 2013) .

Pada pengolahan kakao usaha kecil dan menengah diketahui bahwa proses pengepresan lemak dan pembubukan adalah proses yang memerlukan biaya dan energi paling besar. Selain itu kapasitas dan kinerja alat pengepres dan pembubuk pada umumnya rendah sehingga proses 
ini menjadi bottle neck bagi proses produksi lemak dan bubuk kakao. Manalu et al. (2017) telah mengkaji suatu metode yang melewati dua proses tersebut dalam memproduksi cokelat, yaitu dengan membuat produk cokelat langsung dari pasta kakao. Metode tersebut disebut dengan proses pintas yang menghasilkan produk bermutu baik karena masih mengandung lemak kakao asli. Pasta kakao hasil proses pintas memiliki titik leleh (melting point) yang rendah pada temperatur ruang karena kristal lemaknya belum stabil sehingga perlu dilakukan suatu proses yang dapat meningkatkan titik lelehnya. Hal ini berbeda dengan produk cokelat yang menggunakan lemak nabati yang sudah stabil. Proses tempering merupakan suatu proses yang dapat digunakan untuk meningkatkan titik leleh cokelat. Proses ini melibatkan serangkaian tahapan meliputi pemanasan, pendinginan dan pengadukan dengan kecepatan rendah. Dengan tempering produk cokelat yang dihasilkan juga akan terlihat mengkilap dan tahan terhadap blooming atau lapisan putih seperti jamur yang terdapat diatas permukaan lapisan cokelat (Silva et al., 2017; Indarti et al., 2013). Proses tempering yang benar akan memudahkan cokelat mengeras ketika dicetak dan akan memberikan senasasi rasa dingin yang menyenangkan di mulut. Tempering membantu melepaskan rasa cokelat dengan maksimal (Afoakwa et al., 2008).

Karakteristik kelelehan cokelat sangat dipengaruhi oleh komponen lemak kakaonya. Sebagian besar komponen asam lemak dalam lemak kakao tersusun atas trigliserida yang dapat membentuk beberapa polimorf stabil. Trigliserida tersebut membentuk fork configuration sehingga mampu membentuk kristal dengan bentuk yang berbeda (Okude dan Takiyama, 2015; Afoakwa et al., 2009). Titik leleh dan kekerasan produk cokelat berkaitan erat dengan komponen penyusun asam lemak dan proses pengolahannya. Cokelat umumnya meleleh pada temperatur $30-34^{\circ} \mathrm{C}$ bahkan cokelat susu atau cokelat putih meleleh pada temperatur $27^{\circ} \mathrm{C}$. Cokelat memiliki dua sifat utama yang perlu diperhatikan yaitu flavor dan tekstur yang didalamnya tercakup kelelehan, kekerasan

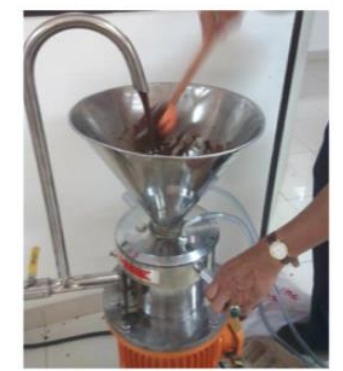

(a)

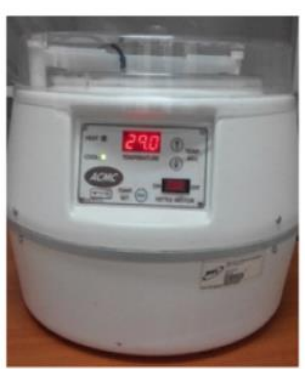

(b)

(hardness) dan kekuatan/kuat lengket (stickiness) (Bolliger dan Windhab, 1999; Sato dan Ueno, 2001).

Cokelat mempunyai cita rasa yang khas, teksturnya yang berbentuk padat pada temperatur kamar, cepat meleleh di mulut dan terasa lembut di lidah. Karakteristik produk cokelat ini dipengaruhi oleh karakteristik kristal lemak cokelat yang terbentuk (Glicerina et al., 2013). Produk cokelat yang baik adalah yang mudah meleleh pada temperatur tubuh manusia tetapi tidak mudah leleh pada temperatur kamar serta memiliki faktor kuat lengket yang minimum.

Penelitian ini bertujuan untuk mengetahui pengaruh proses tempering terhadap titik leleh, kekerasan dan kuat lengket cokelat dark berbasis pasta kakao yang dihasilkan dengan cara pintas. Penelitian ini telah berhasil menentukan kondisi proses (temperatur rendah, temperatur tinggi dan waktu) tempering terbaik dengan menggunakan metode RSM untuk mendapat produk dengan titik leleh, kekerasan dan kuat lengket yang optimum.

\title{
BAHAN DAN METODE
}

\section{Bahan}

Bahan utama penelitian ini adalah pasta kakao yang dihasilkan dengan proses pintas. Bahan baku biji keringnya diperoleh dari UKM di Blitar. Gula halus diperoleh dari gula merk Gulaku sedangkan bahan penunjang adalah lesitin, ekstrak vanila (merk kupu-kupu) dan susu bubuk (Dancow intstan).

\begin{abstract}
Alat
Alat pemasta nib kakao yang digunakan adalah colloid mill (Gambar 1a) sedangkan alat utama dalam percobaan ini adalah mesin tempering merk ACMC yang dilengkapi dengan bowl motor, sensor temperatur dan blower (Gambar 1b). Untuk pencampuran dan penghalusan adonan digunakan alat ball mill yang dilengkapi dengan bola-bola baja (steel balls), pemanas, pompa sirkulasi dan motor pengaduk. Alat yang digunakan untuk analisis karakteristik adalah pengukur titik leleh merek Stuart tipe SMP30 (Gambar 1c) sedangkan untuk mengukur tekstur produk cokelat digunakan alat Texture Analyzer merek TA.XT-Plus (Gambar 1d).
\end{abstract}

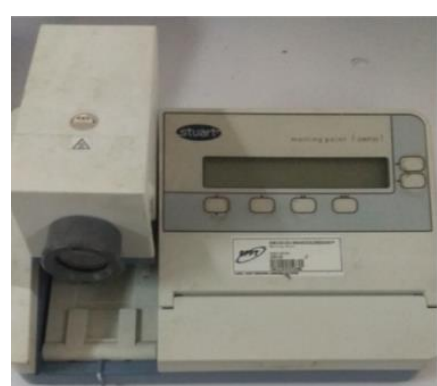

(c)

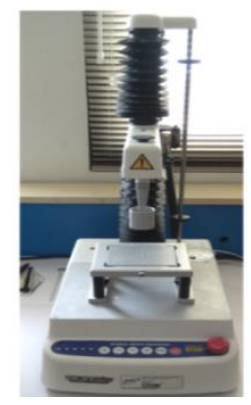

(d)

Gambar-1. Alat penelitian (a) pemasta colloid mill, (b) alat tempering, (c) alat melting point Stuart SMP30, (d) alat texture analyzer TA-XT Plus 
Penelitian dan pengukuran melting point dan Textur Analyzer dilakukan di Laboratorium Pengembangan Teknologi Industri Agro dan Bioteknologi (LAPTIAB), BPPT di Serpong. Faktor atau variabel perlakuan uji tempering dimasukkan kedalam suatu model rancangan percobaan yaitu RSM dengan memasukkan masing-masing variabel batas atas dan bawah dari temperatur tinggi, temperatur rendah dan waktu sehingga rangkaian acak percobaan yang diperoleh oleh metode RSM ini yaitu untuk nilai batas atas terdiri dari temperatur tinggi $\left(45,47,5\right.$ dan $\left.50^{\circ} \mathrm{C}\right)$, temperatur rendah $(29$, 31 dan $\left.33^{\circ} \mathrm{C}\right)$ dan waktu tempering $(10,17,5$ dan 25 menit). Adapun variabel rancangan percobaan yang diperoleh dari metode RSM ini sebagaimana ditampilkan dalam Tabel 1.

Tabel 1. Data variabel percobaan dengan Metode RSM

\begin{tabular}{cccc}
\hline $\begin{array}{c}\text { Run } \\
\text { No. }\end{array}$ & $\begin{array}{c}\text { Faktor } \mathbf{1} \\
\text { Temp. } \\
\text { rendah }\left({ }^{\circ} \mathbf{C}\right)\end{array}$ & $\begin{array}{c}\text { Faktor 2 } \\
\text { Temp. tinggi } \\
\left({ }^{\circ} \mathbf{C}\right)\end{array}$ & $\begin{array}{c}\text { Faktor 3 } \\
\text { Waktu } \\
\text { (menit) }\end{array}$ \\
\hline 1 & 31 & 47,5 & 17,5 \\
2 & 31 & 47,5 & 25,0 \\
3 & 29 & 50,0 & 10,0 \\
4 & 31 & 47,5 & 17,5 \\
5 & 29 & 47,5 & 17,5 \\
6 & 29 & 45,0 & 10,0 \\
7 & 29 & 45,0 & 25,0 \\
8 & 31 & 50,0 & 17,5 \\
9 & 31 & 47,5 & 17,5 \\
10 & 31 & 47,5 & 17,5 \\
11 & 33 & 50,0 & 10,0 \\
12 & 33 & 45,0 & 25,0 \\
13 & 31 & 47,5 & 17,5 \\
14 & 33 & 50,0 & 25,0 \\
15 & 31 & 47,5 & 10,0 \\
16 & 31 & 47,5 & 17,5 \\
17 & 33 & 47,5 & 17,5 \\
18 & 29 & 50,0 & 25,0 \\
19 & 31 & 45,0 & 17,5 \\
20 & 33 & 45,0 & 10,0 \\
\hline
\end{tabular}

\section{Analisis Produk Dark Chocolate}

Analisis sifat fisik terhadap dark chocolate yang dihasilkan meliputi pengukuran titik leleh dan analisi tekstur cokelat meliputi analisa kekerasan (hardness) dan kuat lengket (stickiness) menggunakan alat texture analyzer dengan probe penetrasi jarum $\mathrm{P} / 2$. Penetrasi maksimal dengan tekanan tarik sampel pada kedalaman $5 \mathrm{~mm}$ dilakukan dengan 6 kali ulangan pada kecepatan 1 $\mathrm{mm} / \mathrm{s}$, test $2,0 \mathrm{~mm} / \mathrm{s}$, kecepatan posting $10 \mathrm{~mm} / \mathrm{s}$, pentrasi $5 \mathrm{~mm}$ pada $20^{\circ} \mathrm{C}$

\section{HASIL DAN PEMBAHASAN}

\section{Titik Leleh Dark Chocolate}

Titik leleh cokelat tergantung pada berbagai variabel baik dari proses pengolahannya maupun kandungan/ komposisi dari cokelat itu sendiri. Salah satu proses pengolahan tersebut adalah proses tempering. Pada penelitian ini terdapat tiga faktor yang menjadi variabel perlakuan yaitu suhu tinggi, suhu rendah dan waktu tempering.

Pada Tabel 2 dapat dilihat titik leleh yang diperoleh pada berbagai variabel/faktor percobaan yang dilakukan, dimana hasil observasi dengan titik leleh terendah $34,7^{\circ} \mathrm{C}$ diperoleh pada variasi temperatur rendah $31^{\circ} \mathrm{C}$ dan temperatur tinggi $50^{\circ} \mathrm{C}$ serta waktu tempering 17,5 menit, sedangkan hasil observasi titik leleh tertinggi $36,5^{\circ} \mathrm{C}$ diperoleh pada kondisi proses temperatur rendah $31^{\circ} \mathrm{C}$, temperatur tinggi $47,5^{\circ} \mathrm{C}$ dan waktu tempering 17,5 menit

Tabel 2. Titik leleh (melting point) dark chocolate

\begin{tabular}{ccccc}
\hline Run No. & $\begin{array}{c}\text { Temp. } \\
\text { rendah } \\
\left({ }^{\circ} \mathbf{C}\right)\end{array}$ & $\begin{array}{c}\text { Temp. } \\
\text { tinggi } \\
\left({ }^{\mathbf{0}} \mathbf{C}\right)\end{array}$ & $\begin{array}{c}\text { waktu } \\
(\text { min. })\end{array}$ & $\begin{array}{c}\text { Titik } \\
\text { Leleh } \\
\left({ }^{\mathbf{0}} \mathbf{C}\right)\end{array}$ \\
\hline 1 & 31 & 47,5 & 17,5 & 36,5 \\
2 & 31 & 47,5 & 25,0 & 36,1 \\
3 & 29 & 50,0 & 10,0 & 36,5 \\
4 & 31 & 47,5 & 17,5 & 36,5 \\
5 & 29 & 47,5 & 17,5 & 35,8 \\
6 & 29 & 45,0 & 10,0 & 35,6 \\
7 & 29 & 45,0 & 25,0 & 35,0 \\
$\mathbf{8}$ & $\mathbf{3 1}$ & $\mathbf{5 0 , 0}$ & $\mathbf{1 7 , 5}$ & $\mathbf{3 4 , 7}$ \\
9 & 31 & 47,5 & 17,5 & 36,5 \\
$\mathbf{1 0}$ & $\mathbf{3 1}$ & $\mathbf{4 7 , 5}$ & $\mathbf{1 7 , 5}$ & $\mathbf{3 6 , 5}$ \\
11 & 33 & 50,0 & 10,0 & 35,3 \\
12 & 33 & 45,0 & 25,0 & 35,8 \\
13 & 31 & 47.5 & 17,5 & 36,5 \\
14 & 33 & 50,0 & 25,0 & 35,0 \\
15 & 31 & 47,5 & 10,0 & 34,8 \\
16 & 31 & 47,5 & 17,5 & 36,5 \\
17 & 33 & 47,5 & 17,5 & 36,0 \\
18 & 29 & 50,0 & 25,0 & 35,6 \\
19 & 31 & 45,0 & 17,5 & 36,2 \\
20 & 33 & 45,0 & 10,0 & 35,0 \\
\hline & Sebelum tempering & & 34,5 \\
\hline & & & &
\end{tabular}

Proses tempering merupakan suatu proses pengkondisian yang unik dimana polimorf kristal cokelat yang mengalami perubahan bentuk (transformasi) dapat mempengaruhi besaran titik leleh cokelat. Skema transformasi kristal dari sub- $\alpha$ menjadi $\alpha$, kemudian tumbuh dan bertransformasi menjadi kristal $\beta$ ' terjadi pada saat suhu proses tempering meningkat dari suhu rendah ke tinggi. Transformasi polimorf $\beta$ ' menjadi $\beta$ di peroleh ketika suhu tempering adonan cokelat diturunkan ke suhu rendah atau paling tidak diatas titik leleh dari $\beta$ ' dan dibawah $\beta$. (Ceballos et al., 2016; Smith, 2006)

Dari hasil observasi diperoleh polimorf kristal yang diduga telah bertransformasi menjadi polimorf $\beta$ terjadi pada titik leleh $36,5^{\circ} \mathrm{C}$ pada kondisi proses tempering temperatur rendah $31^{\circ} \mathrm{C}$, temperatur tinggi $47,5^{\circ} \mathrm{C}$ dan waktu tempering 17,5 menit. 


\section{Analisis Tekstur}

Proses tempering yang dilakuan tidak hanya berpengaruh terhadap titik leleh cokelat akan tetapi berpengaruh juga terhadap kekerasan (hardness) dan kuat lengket (stickiness) produk akhir cokelat. Cokelat yang memiliki titik leleh baik belum tentu memiliki tingkat kekerasan yang baik pula. Produk cokelat yang baik adalah yang memiliki karakteristik bila disimpan pada kondisi ruang tidak mudah mengalami deformasi atau tidak mudah mencair, tetapi bila dikonsumsi cokelat mudah mencair pada temperatur tubuh. Dari hasil analisis tekstur yang meliputi kekerasan (hardness) dan kuat lengket (stickiness) diperoleh hasil data pengamatan sebagai berikut (Tabel 3).

Tabel 3. Data hasil pengujian kekerasan (hardness) dan kuat lengket (stickinesss) setelah tempering

\begin{tabular}{|c|c|c|c|}
\hline Run No. & $\begin{array}{c}\text { Titik } \\
\text { Leleh }\left({ }^{0} \mathrm{C}\right)\end{array}$ & Hardness (g) & Stickiness (g) \\
\hline 1 & 36,5 & 746,293 & $-89,491$ \\
\hline 2 & 36,1 & 534,035 & $-50,809$ \\
\hline 3 & 36,5 & 1154,782 & $-61,420$ \\
\hline 4 & 36,5 & 746,293 & $-89,491$ \\
\hline 5 & 35,8 & 851,786 & $-67,647$ \\
\hline 6 & 35,6 & 1547,105 & $-67,215$ \\
\hline 7 & 35,0 & 1029,794 & $-62,449$ \\
\hline 8 & 34,7 & 727,345 & $-67,851$ \\
\hline 9 & 36,5 & 746,293 & $-89,491$ \\
\hline 10 & 36,5 & 746,293 & $-89,491$ \\
\hline 11 & 35,3 & 443,183 & $-53,528$ \\
\hline 12 & 35,8 & 1176,501 & $-66,554$ \\
\hline 13 & 36,5 & 746,293 & $-89,491$ \\
\hline 14 & 35,0 & 1549,24 & $-81,195$ \\
\hline 15 & 34,8 & 772,002 & $-97,169$ \\
\hline 16 & 36,5 & 746,293 & $-89,491$ \\
\hline 17 & 36,0 & 807,484 & $-65,665$ \\
\hline 18 & 35,6 & 1000,96 & $-63,758$ \\
\hline 19 & 36,2 & 682,239 & $-63,034$ \\
\hline 20 & 35,0 & 893,381 & $-63,059$ \\
\hline
\end{tabular}

Dari hasil uji tekstur yang dilakukan terhadap variabel terpilih yaitu pada titik leleh terendah $34^{\circ} \mathrm{C}$ didapatkan nilai kekerasan 772,002 g dan kuat lengket sebesar-97,169 g, sedangkan pada titik leleh tertinggi $36,5^{\circ} \mathrm{C}$ nilai kekerasan struktur kristal mencapai 746,923 g dan kuat lengket (stickiness) -89,941 g.

Dari hasil pengukuran titik leleh yang dilakukan dan dibandingkan dengan kekerasan dan kuat lengket cokelat dapat dilihat bahwa pada titik leleh $36,5^{\circ} \mathrm{C}$ tingkat kekerasan cokelat adalah medium yaitu 746,293 g dan kuat lengket agak tinggi, yaitu mencapai $-89,491 \mathrm{~g}$ (percobaan run 1 dan 4). Berdasarkan nilai tersebut dapat dilihat bahwa walaupun titik leleh cokelat sama tetapi tingkat kekerasan dan kuat lengket cokelat bisa berbeda. Pengaruh proses tempering terhadap parameter kekerasan cokelat disini dapat dipelajari lebih jauh dengan membandingkan Tabel 2 dan 3 . Pada saat proses tempering dilakukan terlihat bahwa cokelat pertama kali dilelehkan hingga temperature $50^{\circ} \mathrm{C}$ dengan waktu tempering 10 menit kemudian didinginkan hingga $29^{\circ} \mathrm{C}$. Pada kondisi tersebut dihasilkan produk cokelat dengan tingkat kekerasan yang cukup besar yakni 1154,782 g dibandingkan dengan kondisi proses tempering yang dilakukan pada temperatur $47,5^{\circ} \mathrm{C}$ selama 17,5 menit kemudian didinginkan hingga $31^{\circ} \mathrm{C}$ dihasikan cokelat dengan titik leleh $36,5^{\circ} \mathrm{C}$ dengan kekerasan yang medium/tidak terlalu keras yakni 746,647 g.

\section{Analisis Varian (Anova)}

Dari hasil anova terhadap hubungan data titik leleh yang diperoleh berdasarkan variabel faktor (temperatur rendah, temperatur tinggi dan waktu tempering) dengan model Quadratic, pemilihan model dengan bentuk Quadratic merupakan model yang disarankan oleh Response Surface Model (RSM) dimana kesimpulan statistik dari model yang disarankan pada hasil kesimpulan model yang digunakan dapat dilihat pada Tabel 4.

Tabel 4 dapat dilihat bahwa metode analisis data yang disarankan menggunakan model persamaan kuadratik dimana hasil analysis of varians (ANOVA) terhadap ketiga respon menunjukkan bahwa terdapat hubungan yang signifikan antara variabel model terhadap respon kekerasan (hardness) sedangkan untuk respon titik leleh dan kuat lengket (stickiness) tidak menunjukkan hubungan yang signifikan. Dari hasil analisa variannya (ANOVA) respon kekerasan terhadap faktor temperatur rendah dan tinggi serta waktu menunjukan nilai Prob $>\mathrm{F}<0,05$ atau 0,0013 $<0,05$.

Pada Gambar 2 disajikan kurva respon permukaan (response surface) titik leleh terhadap kekerasan dan kuat lengket sebagai fungsi dari variabel temperatur rendah dan tinggi pada waktu tempering 17,5 menit. Respon titik leleh semakin tinggi dengan meningkatnya suhu tempering tinggi hingga satu titik maksimum dan kemudian turun kembali seiring meningkatnya suhu (Gambar 2(a)). Untuk respon kuat lengket dan kekerasan terlihat bahwa kedua respon menuju satu titik optimum (minimum) pada satu kombinasi variabel suhu tinggi dan rendah yaitu masing-masing $47,5^{\circ} \mathrm{C}$ dan $31^{\circ} \mathrm{C}$ (Gambar 2(b) dan 2(c)). 
Tabel 4. Hasil Anova untuk Response Surface Method dengan model Quadratic

\begin{tabular}{|c|c|c|c|c|c|}
\hline \multicolumn{6}{|c|}{ Titik Leleh (Melting Point) } \\
\hline \multirow[b]{2}{*}{ Source } & & \multirow{2}{*}{$\begin{array}{l}\text { Mean } \\
\text { Square }\end{array}$} & \multirow{2}{*}{$\begin{array}{l}\text { F } \\
\text { Value }\end{array}$} & \multirow{2}{*}{$\begin{array}{l}\text { p-value } \\
\text { Prob }>F\end{array}$} \\
\hline & Squares & $d f$ & & & \\
\hline Model & 4,54 & 9 & 0,50 & 1,39 & $\begin{array}{l}0,3076 \\
\text { tidak signifikan }\end{array}$ \\
\hline A-Temp. Rendah & 0,20 & 1 & 0,20 & 0,54 & 0,4796 \\
\hline B-Temp. Tinggi & 0,025 & 1 & 0,025 & 0,069 & 0,7984 \\
\hline C-Waktu & $9,00 \mathrm{E}+00$ & 1 & $9,00 \mathrm{E}+00$ & 0,025 & 0,8781 \\
\hline Residual & 3,63 & 10 & 0,36 & & \\
\hline Lack of Fit & 3,63 & 5 & 0,73 & & \\
\hline Pure Error & 0,000 & 5 & 0,000 & & \\
\hline Cor Total & 8,17 & 19 & & & \\
\hline \multicolumn{6}{|c|}{ Kekerasan (Hardness) } \\
\hline & Sum of & & Mean & $\mathrm{F}$ & p-value \\
\hline Source & Squares & df & Square & Value & Prob > F \\
\hline Model & $1,41 \mathrm{E}+09$ & 9 & $1,56 \mathrm{E}+08$ & 8.44 & $\begin{array}{l}0,0013 \\
\text { signifikan }\end{array}$ \\
\hline A-Temp. Rendah & 51076.04 & 1 & 51076.04 & 2,76 & 0,1277 \\
\hline B-Temp. Tinggi & 20563.96 & 1 & 20563.96 & 1,11 & 0,3167 \\
\hline C-Waktu & 23050.08 & 1 & 23050.08 & 1,25 & 0,2906 \\
\hline Residual & $1,85 \mathrm{E}+08$ & 10 & 18510.74 & & \\
\hline Lack of Fit & $1,85 \mathrm{E}+08$ & 5 & 37021.48 & & \\
\hline Pure Error & 0.000 & 5 & 0,000 & & \\
\hline Cor Total & $1,59 \mathrm{E}+09$ & 19 & & & \\
\hline \multicolumn{6}{|c|}{ Kuat lengket (Stickiness) } \\
\hline & Sum of & & Mean & $\mathrm{F}$ & p-value \\
\hline Source & Squares & $\mathrm{df}$ & Square & Value & Prob $>$ F \\
\hline Model & 2041,46 & 9 & 226,83 & 1,24 & $\begin{array}{l}0,3670 \\
\text { tidak signifikan }\end{array}$ \\
\hline A-Temp. Rendah & 5,64 & 1 & 5,64 & 0,031 & 0,8638 \\
\hline B-Temp. Tinggi & 2,96 & 1 & 2,96 & 0,016 & 0,9011 \\
\hline C-Waktu & 31,07 & 1 & 31,07 & 0,17 & 0,6884 \\
\hline Residual & 1822,68 & 10 & 182,27 & & \\
\hline Lack of Fit & 1822,68 & 5 & 364,54 & & \\
\hline Pure Error & 0,000 & 5 & 0,000 & & \\
\hline Cor Total & 3864,14 & 19 & & & \\
\hline
\end{tabular}

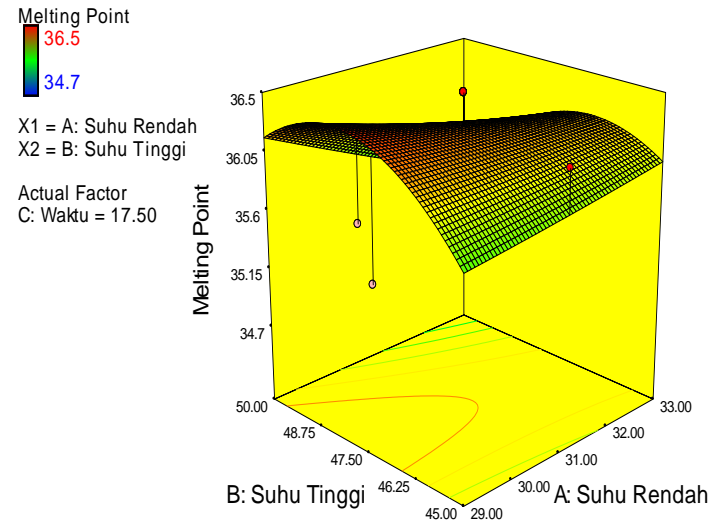

(a)

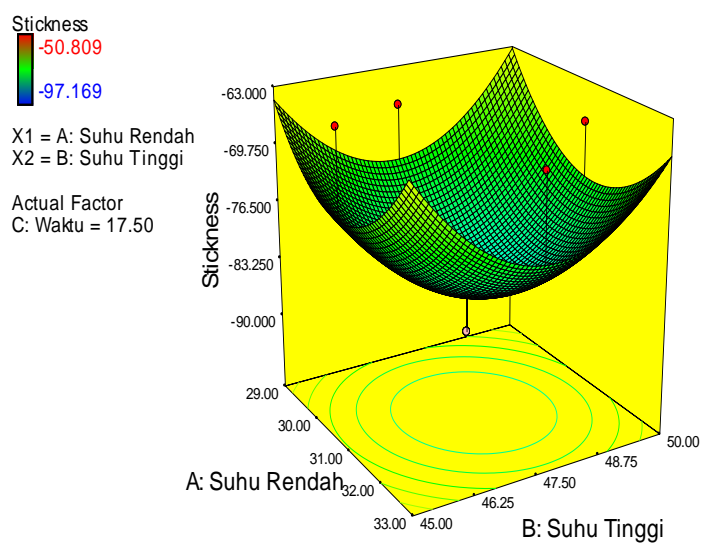

(b) 


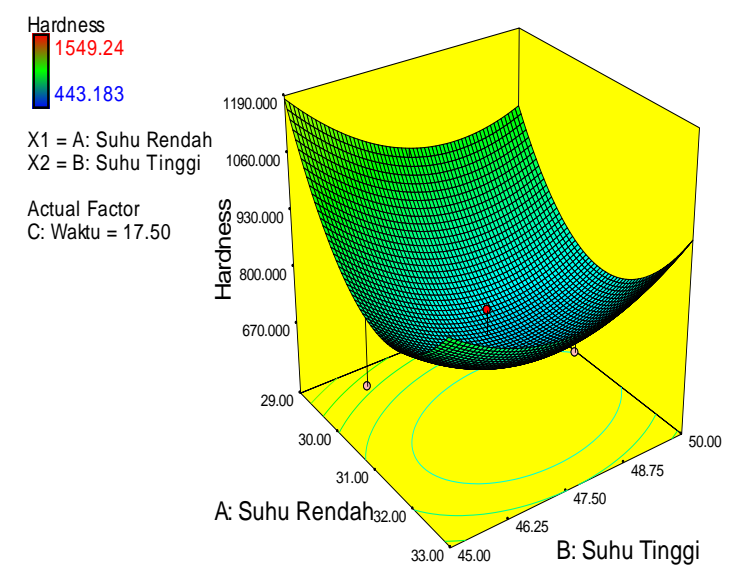

(c)

Gambar 2. (a). Kurva RSM parameter titik leleh, (b). kekerasan dan (c). stickiness

\section{KESIMPULAN DAN SARAN}

\section{Kesimpulan}

Tempering merupakan proses yang berpengaruh terhadap kualitas produk cokelat dark yang dihasilkan. Hasil kajian menunjukkan kondisi proses tempering yang optimum adalah pada temperatur rendah $31^{\circ} \mathrm{C}$, temperatur tinggi $47,5^{\circ} \mathrm{C}$ dan waktu tempering 17,5 menit. Pada kondisi tersebut titik leleh cokelat dark $36,5^{\circ} \mathrm{C}$, kekerasan 746,23 g dan kuat lengket (stickiness) -89,491 g. Hasil analysis of varians (anova) terhadap ketiga respon menunjukkan bahwa terdapat hubungan yang signifikan antara ketiga variabel model terhadap respon kekerasan (hardness), sedangkan untuk titik leleh (melting point) dan kuat lengket (stickiness), ketiga faktor percobaan tidak menunjukkan pengaruh yang signifikan terhadap respon.

\section{Saran}

Untuk melihat lebih jauh hubungan antara ketiga variabel model terhadap respon kekerasan perlu dilakukan penelitian lanjutan.

\section{UCAPAN TERIMA KASIH}

Penulis menyampaikan terima kasih kepada BPPT dan Kementerian Riset Teknologi dan Pendidikan Tinggi Republik Indonesia (Kemenristekdikti RI) atas fasilitas Laboratorium penelitian dan dana penelitian melalui Program Insinas 2017.

\section{DAFTAR PUSTAKA}

Afoakwa EO, Paterson A, Fowler M, Vieira J. 2008. Effects of tempering and fat crystallisation behaviour on microstructure, mechanical properties and appearance in dark chocolate systems. Journal Food Engineering. 89: 128-136.
Afoakwa EO, Paterson A, Fowler M, Vieira J. 2009. Influence of tempering and fat crystallization behaviours on microstructural and melting properties in dark chocolate systems. Food Research International. 42: 200-209.

Bolliger SZ dan Windhab EJ. 1999. In-line measurement of tempered cocoa butter and chocolates by means of near - infrared spectroscopy. Journal America oil Chemist Society. 6(6): 659-667.

Ceballos MR, Bierbrauer K, Faudone SN, Cuffini SL, Beltramo DM, Bianco ID. 2016. Influence of ethylcellulose- Medium chain triglycerides blend on the flow behavior and $\beta-\mathrm{V}$ polymorph retention of dark chocolate. Food Structure.10: 1-9.

Glicerina V, Balestra F, Rosa MD, Romani S. 2013. Rheological, textural and calorimetric modifications of dark chocolate during process. Journal Food Engineering. 119: 173-179.

Indarti E dan Arpi BS. 2013. Kajian pembuatan cokelat batang dengan metode tempering dan tanpa tempering. Unsyiah, Banda Aceh. Indonesia

Jahurul MHA, Zaidul ISM, Norulaini NAN, Sahena F, Jinap S, Azmir J, Sharif KM. 2013. Cocoa butter fats and possibilities of substitution in food products concerning cocoa varieties, alternative sources, extraction methods, composition, and characteristics. Journal Food Engineering. 117 : 467-476.

Lipp M dan Anklam E. 1998. Review of cocoa butter and alternative fats for use in chocolate - Part A. Compositional Data. Journal Food Chemistry. 62 (1): 73-97

Manalu LP, Atmaji G, Wibowo T, Yani A. 2013. Penerapan teknologi produksi cokelat compound skala UKM di koridor ekonomi 
sulawesi. Prosiding Seminar Insinas Ristek 2013. Jakarta, 7-8 Nopember 2013.

Manalu LP, Djafar MJ, Wibowo TY, Adinegoro H. 2017. Proses pintas pengolahan kakao skala UKM Studi kasus di Luwu Sul-sel. Majalah Pengkajian Industri.11 (1): 51-60.

Manalu LP. 2016. Studi peran riset dan pengembangan dalam mendukung industri kakao nasional. Majalah Pengkajian Industri. 10 (1): 19-26.

Okude A dan Takiyama H. 2015. Selective recrystallization of metastable polymorph of melt acetaminophen by using tempering operation. Journal Industrial and Engineering Chemistry. 31: 263-268.
Sato K dan Ueno S. 2001. Molecular interactions and phase behavior of polymorphic fats: In: Garti N., Sato K., (eds.), Crystallization Processes in Fats and Lipid Systems, New York: Marcel Dekker.

Silva TLT, Grimaldi R, dan Gonçalves LAG. 2017. Temperature, time and fat composition effect on fat bloom formation in dark chocolate. Food Structure. 14 : 68-75.

Smith K. 2006. Chocolate tempering, Presented at the Confectionery Manufacturing Expo, Brusel, Belgium on June 2006. Diakses lewat daring https://courses. ecolechocolat.com/lobjects/pdf/belgium_te mpering.pdf [di akses 20 Maret 2017]. 